\title{
(C) OPEN ACCESS \\ Secondary prevention therapies in acute coronary syndrome and relation to outcomes: observational study
}

\author{
Clara K Chow, ${ }^{1,2}$ David Brieger, ${ }^{3}$ Mark Ryan, ${ }^{4}$ Nadarajah Kangaharan, ${ }^{5}$ Karice K Hyun, ${ }^{6}$ \\ Tom Briffa, ${ }^{2}$ for the CONCORDANCE Investigators
}

\begin{abstract}
${ }^{1}$ Westmead Applied Research Centre, Faculty of Medicine \& Health, University of Sydney, Sydney, New South Wales, Australia

${ }^{2}$ The George Institue of Global Health, Perth, Western Australia, Australia

${ }^{3}$ Concord Repatriation General Hospital \& The University of Sydney, Sydney, New South Wales, Australia

${ }^{4}$ Deparatment of Cardiology, Shoalhaven District Memorial Hospital, Nowra, New South Wales, Australia

${ }^{5}$ Royal Darwin Hospital, Casuarina, Northern Territory, Australia

${ }^{6}$ ANZAC Research Institute, Sydney Medical School, University of Sydney, Sydney, Australia
\end{abstract}

\section{Correspondence to}

Dr Clara K Chow, Department of Cardiology, Westmead Applied Research Centre and Faculty of Medicine \& Health, Westmead Hospital, University of Sydney, Sydney, Australia; cchow@ georgeinstitute.org.au; clara. chow@sydney.edu.au

Received 18 September 2018 Revised 30 October 2018 Accepted 1 November 2018

\section{ABSTRACT}

Objective To ascertain the use of secondary prevention medications and cardiac rehabilitation after an acute coronary syndrome (ACS) and the impact on 2-year outcomes.

Methods CONCORDANCE (Cooperative National Registry of Acute Coronary care, Guideline Adherence and Clinical Events) is a prospective, observational registry of 41 Australian hospitals. A representative sample of 6859 patients with an ACS and 6 months' follow-up on 31 May 2016 were included. The main outcome measure was use of $\geq 75 \%$ of indicated medications ( $\geq 4 / 5$ (or $\geq 3 / 4$ if contraindicated) of angiotensin-converting enzyme (ACE) inhibitor/ angiotensin receptor blocker, beta-blocker, lipidlowering therapy, aspirin and other antiplatelet). Major adverse cardiovascular events (MACE) included myocardial infarction, stroke or cardiovascular death. Results The mean age was $65 \pm 13$ years, $29 \%$ were women, and the mean Global Registry of Acute Coronary Events (GRACE) score was $106 \pm 30$. At discharge, $92 \%$ were on aspirin, $93 \%$ lipid-lowering therapy, 78\% beta-blocker, 74\% ACE/angiotensin receptor blocker and $73 \%$ a second antiplatelet; $89 \%$ were taking $\geq 75 \%$ of medications at discharge, $78 \%$ at 6 months and $66 \%$ at 2 years. At 6 months, 38\% attended cardiac rehabilitation, $58 \%$ received dietary advice and $32 \%$ of smokers reported quitting. Among 1896 patients followed to 2 years, death/MACE was less frequent among patients on $\geq 75 \%$ vs $<75 \%$ of medications (8.3\% vs $13.9 \%$; adjusted OR $0.75,95$ $\% \mathrm{Cl} 0.56$ to 0.99 ), and was less frequent in patients who attended versus who did not attend cardiac rehabilitation (4.6\% vs $13.4 \%$; adjusted OR 0.44 , $95 \% \mathrm{Cl} 0.31$ to 0.62 ).

Conclusions Use of secondary prevention therapies diminishes over time following an ACS. Patients receiving secondary prevention had decreased rates of death and MACE at 2 years.

\section{Check for updates}

(C) Author(s) (or their employer(s)) 2019. Re-use permitted under CC BY-NC. No commercial re-use. See rights and permissions. Published by BMJ.

To cite: Chow CK, Brieger D, Ryan $\mathrm{M}$, et al. Heart Asia 2019;11. doi:10.1136/

heartasia-2018-011122

\section{INTRODUCTION}

Patients with an acute coronary syndrome (ACS) have an adjusted 5-year risk of subsequent ischaemic events approximately 20\% higher in absolute terms than persons without coronary heart disease. ${ }^{1}$ Secondary prevention treatments, including behavioural advice (diet, exercise and smoking cessation) and cardioprotective medications (aspirin or other antiplatelet, beta-blockers, statins, angiotensin-converting enzyme (ACE) inhibitors or angiotensin II receptor blockers), are

\section{Key messages}

What is already known about this subject?

- Gaps exist between evidence-based recommendations and use of secondary prevention medications after an acute coronary syndrome (ACS).

\section{What does this study add?}

- At discharge, $89 \%$ of patients with ACS were taking $\geq 75 \%$ of indicated medications, but this fell to $78 \%$ at 6 months and $66 \%$ at 2 years.

- Death/myocardial infarction/stroke was significantly less frequent among patients on $\geq 75 \%$ vs $<75 \%$ of medications after 2 years of follow-up.

How might this impact on clinical practice?

- This study highlights the rapidly declining use of secondary prevention medications after an ACS in Australia.

- This issue should be addressed urgently in Australia in order to improve patient outcomes.

effective in reducing the risk of repeat ischaemic events in ACS. $^{2-4}$ In addition, large systematic reviews find that participation in programmes that address multiple components of secondary prevention lowers all-cause mortality (relative risk $0.87,95 \% \mathrm{CI} 0.63$ to 0.87 ) at 12 months and beyond, and reduces the risk of hospital admissions (relative risk $0.69,95 \% \mathrm{CI} 0.51$ to 0.93 ) to 12 months. ${ }^{56}$

Several studies have demonstrated large gaps between evidence-based recommendations and the use of medications for secondary prevention after an ACS. ${ }^{7-9}$ The Australian Cooperative National Registry of Acute Coronary care, Guideline Adherence and Clinical Events (CONCORDANCE) registry is an investigator-initiated, prospective, observational study that describes the management and outcomes of patients with an ACS in Australian hospitals. ${ }^{10}$ In the present analysis, we describe the receipt of cardiovascular prevention care, including medications before hospitalisation, at discharge from hospital after the index event, at 6 months and at 2 years. We also explore the relationship between (1) attendance at cardiac rehabilitation in the 6 months after the index event, and (2) use of cardiovascular prevention treatments at discharge to 6 months and major adverse cardiovascular events 
(MACE), revascularisation, and all-cause or cardiovascular death at 2 years.

\section{METHODS}

The CONCORDANCE registry is an ongoing clinician-led, prospective, observational study being conducted at 41 hospitals in Australia. ${ }^{10}$ The registry has been designed within a comparative effectiveness research framework to collect and report data from hospitals located in geographically diverse regions of Australia that are representative of regional and metropolitan acute care facilities, with a range of clinical and treatment characteristics, procedural services and hospital systems. ${ }^{10}$ Continuous real-time reporting on the clinical characteristics, management and outcomes of patients with ACS is provided to clinicians, hospital administrators and sponsors/interested stakeholders, and if required to the government.

A purposive sampling strategy was adopted to include hospitals serving indigenous patients, hospitals in metropolitan, rural and remote locations, and hospitals with or without cardiac catheterisation or percutaneous coronary intervention capabilities. Hospitals that had demonstrated the ability to implement quality initiatives were also identified and invited to participate. To obtain a representative sample of the ACS population, a pragmatic approach to sampling was adopted, with the first 10 consecutive patients admitted with an ACS at the beginning of each month included. An opt-out consent process and consent waiver for patients who died or were too ill to consent also minimised bias. ${ }^{10}$

\section{Participants}

Participants needed to meet clearly defined inclusion criteria. Patients ( $>18$ years) were eligible if they presented to hospital with symptoms consistent with acute cardiac ischaemia lasting for $>10$ min occurring within 24 hours of presentation and had one of the following: electrocardiographic changes (transient ST-segment elevation of $0.5 \mathrm{~mm}$ in $\geq 2$ contiguous leads; ST-segment depression of $0.5 \mathrm{~mm}$ in $\geq 2$ contiguous leads; new T-wave inversion of $1 \mathrm{~mm}$ in $\geq 2$ contiguous leads; new $\mathrm{Q}$ waves (one-third the height of R-wave or $>0.04 \mathrm{~s}$ ); new $\mathrm{R}$-wave $>\mathrm{S}$-wave in lead V1 (posterior myocardial infarction); or new left bundle branch block); elevated cardiac biomarkers (increase in troponin $\mathrm{T}$ or I above the upper limit of normal; creatine kinase $\mathrm{MB}$ fraction $2 \times$ the upper limit of normal or total creatine kinase above the upper limit of normal); history of coronary artery disease; new documentation of coronary artery disease; or two features of high-risk ACS (blood pressure $<90$ $\mathrm{mm} \mathrm{Hg}$ and heart rate $>100$ beats/min); left ventricular ejection fraction $<40 \%$; known diabetes; and documented chronic kidney disease (estimated glomerular filtration rate $<60 \mathrm{~mL} /$ min). Documented coronary artery disease was defined as one of the following: history of myocardial infarction, angina, congestive cardiac failure due to ischaemia or resuscitated sudden cardiac death; history of or new positive stress test with or without imaging; previous or new cardiac catheterisation documenting coronary artery disease; or previous or new percutaneous coronary intervention or coronary artery bypass graft surgery.

Patients with an ACS precipitated by a non-cardiovascular condition such as anaemia or by trauma were excluded. For the current analyses, we restricted the study population to patients discharged alive with a definite diagnosis of ACS who were followed to 6 months and to 2 years.

\section{Data collection}

An electronic clinical record form was used to enter data into a web-based database. The data captured included patient demographics, presenting characteristics, medical history, in-hospital management and clinical outcomes at 6 months and 2 years, and were collected during patient interview and by review of medical records. During follow-up, data were collected on vital status, medication compliance, participation in cardiac rehabilitation programmes and cardiovascular disease risk reduction interventions.

\section{Data management, security and registry governance}

Data are managed by The George Institute for Global Health. At start-up, patients (or their relatives) were required to provide written informed consent. An opt-out consent process and a consent waiver for patients who died or were too ill to provide consent was subsequently approved. ${ }^{10}$

The registry is directed by a nationally representative Steering Committee comprising representatives from the participating centres and other members with expertise in clinical registries, bench research and public health.

\section{Study outcomes}

The first study outcome was the rate of receipt of cardiovascular prevention care, including medications before the index event, during hospitalisation, at discharge, and at 6 months and at 2 years (for the subsets with data available). We summarised cardiovascular prevention treatments as the proportion on $\geq 75 \%$ of indicated medications. This could be four or five of five medications, or three or four of four medications (if five were not indicated):

1. Aspirin for all.

2. Lipid-lowering therapy for all.

3. Antiplatelet for all patients with ST-segment elevation myocardial infarction (STEMI) or non-STEMI (NSTEMI) or undergoing percutaneous coronary intervention. For patients with unstable angina, a second antiplatelet is generally indicated if the patient is aged $>60$ years, has had a previous myocardial infarction or undergone coronary artery bypass graft surgery, has multivessel coronary artery disease, previous stroke or transient ischaemic attack or peripheral vascular disease, or has chronic kidney disease. A second antiplatelet is not indicated for patients on a vitamin $\mathrm{K}$ antagonist or non-vitamin $\mathrm{K}$ oral anticoagulant unless the patient is not on aspirin.

4. Beta-blocker for all patients unless they have heart block or unstable angina and their left ventricular function is normal.

5. ACE inhibitor or angiotensin receptor blocker for all patients unless they are allergic to the medication or have unstable angina and their left ventricular function is normal.

The secondary outcome was to explore the relationship between use of cardiovascular prevention treatments at discharge to 6 months (defined as reporting taking $\geq 75 \%$ of indicated medications at discharge and 6 months) and attendance at cardiac rehabilitation (defined as reporting attendance during the 6 months postindex event) with occurrence of (1) MACE, defined as a composite of myocardial infarction, stroke or cardiovascular death; (2) all-cause or cardiovascular mortality; and (3) any readmissions for heart disease and/or major bleeding events.

\section{Statistical analyses}

For the first outcome, we restricted the cohort to patients who had a confirmed discharge diagnosis of ACS, were discharged from hospital and had completed 6 months of follow-up as of 31 


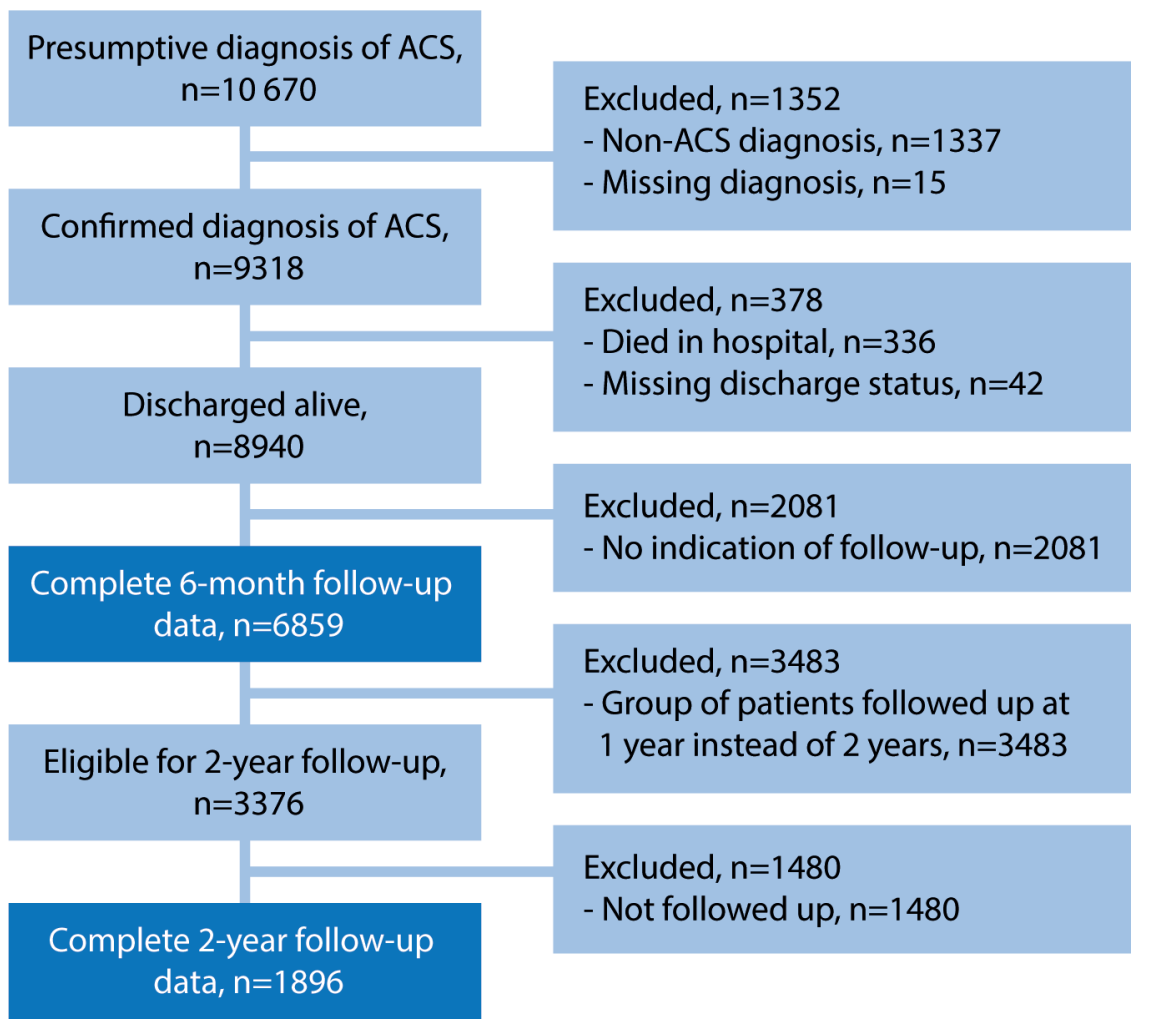

Figure 1 Patient flow chart. ACS, acute coronary syndrome.

May 2016. Data were $>98 \%$ complete for all baseline variables; missing data were coded as the median value.

We conducted descriptive analyses and compared subgroups stratified by age, sex and ACS type (STEMI, NSTEMI or unstable angina). Continuous variables are reported as mean and SD and were tested using t-test. Categorical variables are reported as frequencies and percentages and were tested using the $\chi^{2}$ test. For the second outcome, we restricted the cohort to those who were followed for $\geq 2$ years after their cardiovascular event.

We used multivariable logistic generalised estimating equations analysis with exchangeable working correlation matrix to account for the clustering effect of hospital to examine whether use of $\geq 75 \%$ of secondary prevention medications at 6 months was associated with the occurrence of MACE, revascularisation, and all-cause or cardiovascular mortality at 2 years. We adjusted for individual factors known to be associated with MACE and hospital-level characteristics (age, sex, revascularisation (percutaneous coronary intervention/coronary artery bypass graft), previous cardiovascular disease (medical history of myocardial infarction, stroke and peripheral artery disease) and Global Registry of Acute Coronary Events risk score). ${ }^{11}$

\section{RESULTS}

A total of 10670 individuals were enrolled in CONCORDANCE with a presumptive diagnosis of ACS between February 2009 and May 2016: 6859 patients had a final diagnosis of ACS (STEMI in 2078 (30.3\%), NSTEMI in 3324 (48.5\%) and unstable angina in $1457(21.2 \%)$ ), and were discharged and followed up at 6 months (figure 1). Follow-up to 2 years was complete in 1896 (56.2\%) of 3376 eligible patients. The baseline characteristics of the patients, overall and according to final diagnosis, receipt of all indicated secondary prevention therapies, and cardiac rehabilitation attendance, are detailed in table 1 .

\section{Secondary prevention treatments}

Forty-two per cent of patients were on aspirin before arrival at hospital. The percentage on aspirin rose to $96 \%$ during hospitalisation and $92 \%$ at discharge (table 2). The rate of aspirin use decreased to $80 \%$ at 6 months after discharge and to $71 \%$ at 2 years (figure 2A). Similar patterns were observed for the other cardioprotective medications.

Before hospitalisation, $49 \%$ of patients were taking $<40 \%$ of indicated cardioprotective medications; this figure fell to $1 \%$ during hospitalisation and increased to $21 \%$ at 2 years (figure 2A). The patterns were similar when the cohort was restricted to patients with STEMI or NSTEMI (and excluding patients with unstable angina) (figure $2 \mathrm{~B}$ ).

At discharge, 4438 (65\%) of patients were referred to cardiac rehabilitation. At 6 months, 2607 (38\%) reported cardiac rehabilitation attendance, $58 \%$ reported receiving dietary advice and $32 \%$ of smokers had quit.

\section{Clinical outcomes}

Among the 1896 patients with 2-year follow-up data, 110 (5.8\%) had died, 115 (6.1\%) had experienced MACE and 438 $(23 \%)$ had been hospitalised (table 3 ). After adjustment, receipt of $\geq 75 \%$ of indicated cardioprotective medications in the first 6 months was associated with lower odds of death and MACE and no significant difference in rehospitalisation at 2 years. Similarly, cardiac rehabilitation attendance in the first 6 months was associated with lower rates of death and MACE and no significant difference in hospitalisation (table 3).

\section{DISCUSSION}

With overwhelming evidence on the effectiveness of secondary prevention therapies after ACS, it is reassuring and perhaps not surprising that many patients in hospital and at discharge 


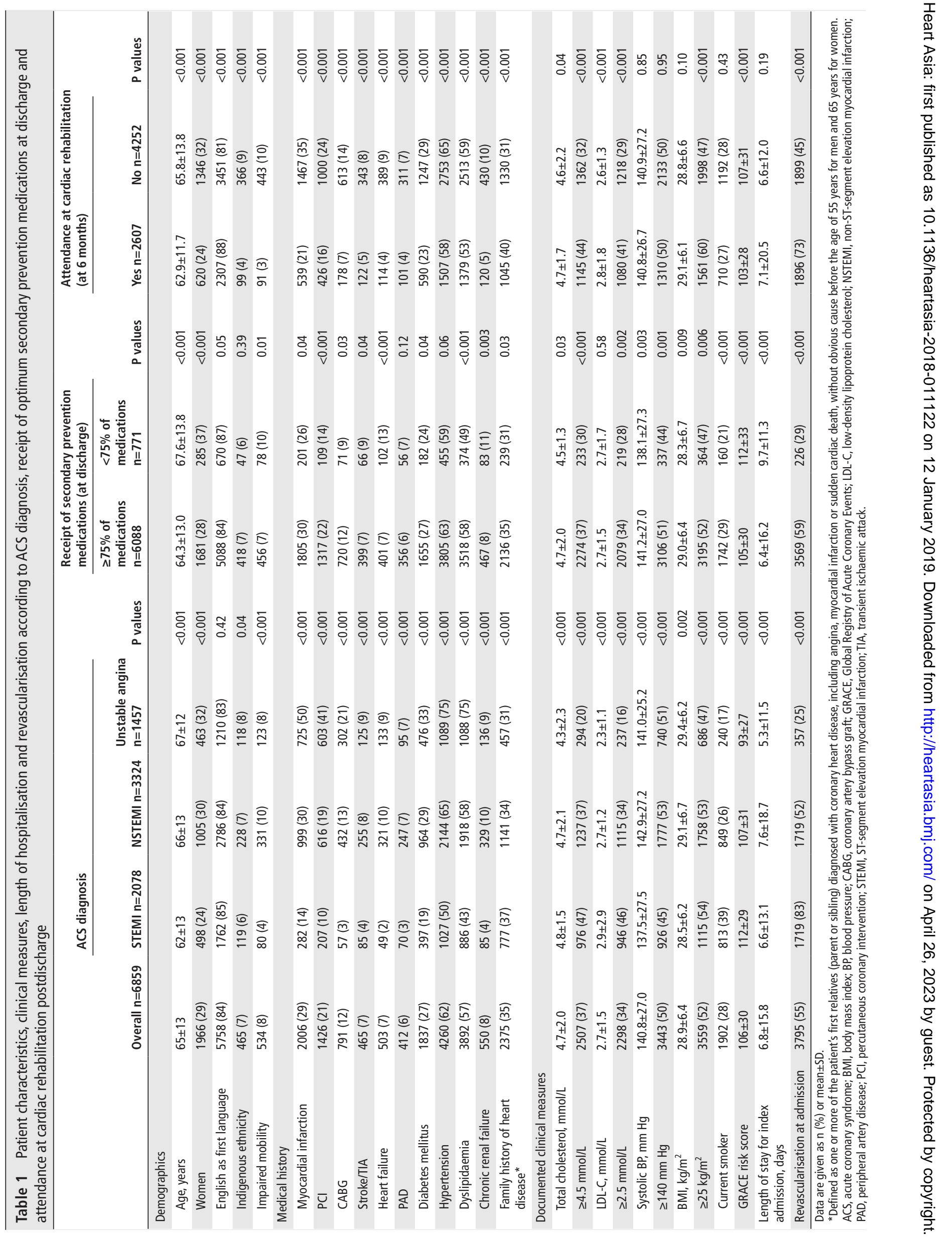




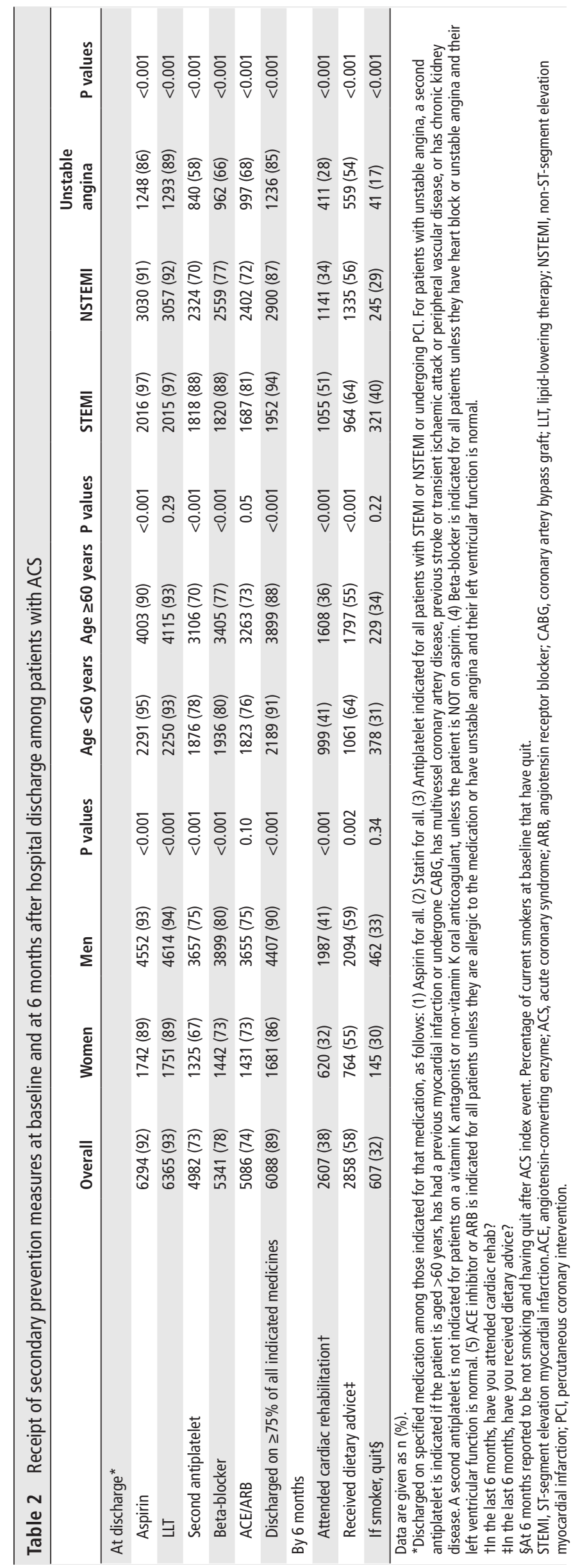


A

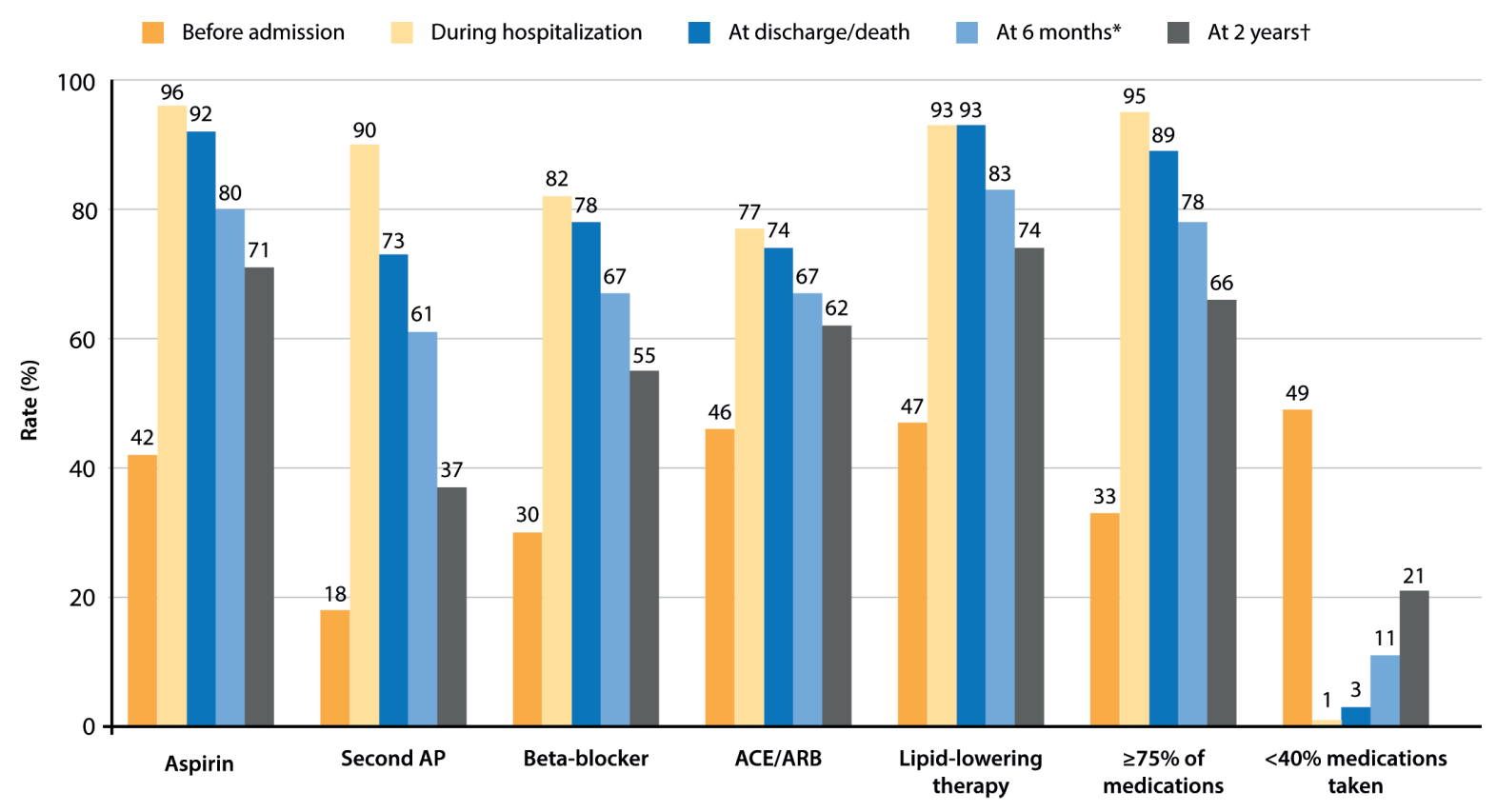

B

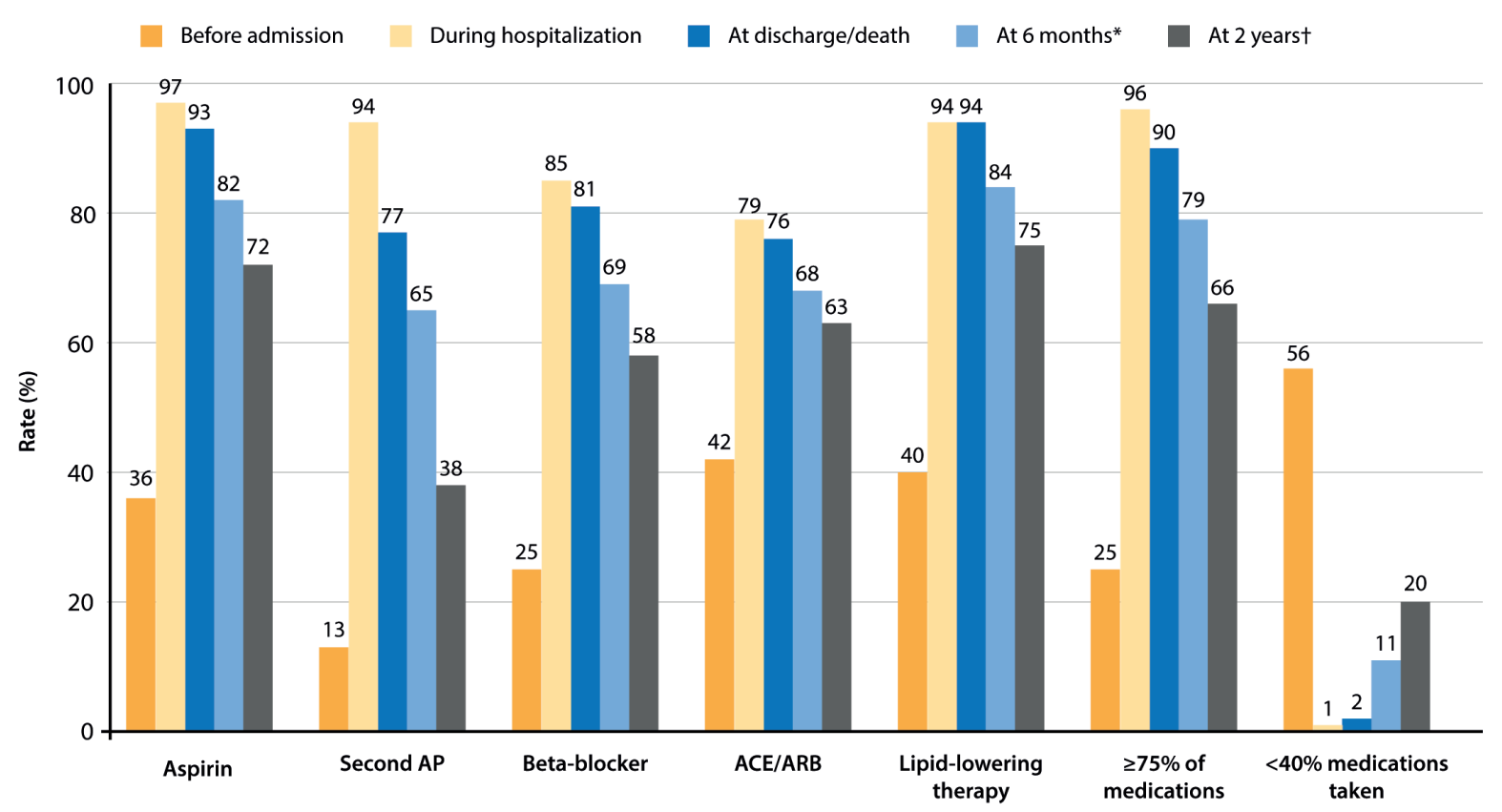

Figure 2 Use of evidence-based cardiac medications before, during and after hospitalisation for the index event in (A) overall ACS population and (B) patients with ST-segment elevation or non-ST-segment elevation myocardial infarction, who were alive at 2 years and had follow-up data. (A) *6595 patients followed up and alive at 6 months. +1786 patients followed up and alive at 2 years. (B) * 5170 patients followed up and alive at 6 months. 11387 patients followed up and alive at 2 years. ACS, acute coronary syndrome; AP, antiplatelet; ARB, angiotensin receptor blocker.

are prescribed these treatments. However, these contemporary Australian observational data demonstrate a substantial decline in use of cardioprotective medications after the index ACS. Whereas at discharge over $90 \%$ of patients were on $\geq 75 \%$ of indicated medications and fewer than $3 \%$ were on $<40 \%$ of medications, by 6 months the proportion on $<40 \%$ of medications had risen to $12 \%$ and at 2 years to $22 \%$. This study also demonstrated a low rate of cardiac rehabilitation attendance (approximately one-third) and low rates of smoking cessation (approximately one-third of current smokers). However, the analysis based on 2-year follow-up data indicates that receipt of secondary prevention medications and attendance at cardiac rehabilitation in the first 6 months are both associated with lower rates of death and MACE at 2 years. Consequently, these 'real-world' data support the benefits of secondary prevention recommendations post-ACS.

The patterns of medication use after discharge from hospital for an ACS in the present study are consistent with reports from other world regions, in that adherence to secondary prevention declines over time. ${ }^{12-14}$ This decline is particularly notable in studies from lower income countries. ${ }^{8}$ However, rates of use of secondary prevention treatments in this Australian study appear substantially 


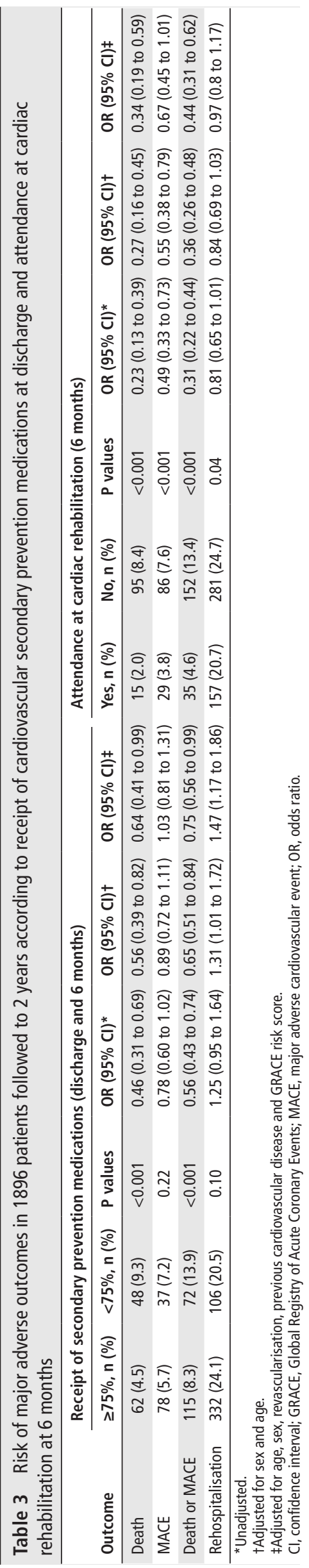

lower than those reported in countries of a similar economic level and development. The rates of use of secondary prevention drugs in our study are substantially lower than those in contemporaneous surveys from European Action on Secondary and Primary Prevention by Intervention to Reduce Events (EUROASPIRE) II and III. ${ }^{15}$ For example, 94\% of patients in EUROASPIRE II and 95\% in EUROASPIRE III were on aspirin 6 months after the index event, compared with $80 \%$ in CONCORDANCE. Similarly, rates of statin use were $89 \%$ in EUROASPIRE II and III, but $83 \%$ at 6 months and $74 \%$ at 2 years in CONCORDANCE. Similar patterns were observed for use of ACE/angiotensin receptor blocker and beta-blockers. ${ }^{15}$ Rates of smoking cessation in the Australian cohort were also substantially lower, with $45 \%$ in EUROASPIRE II and $47 \%$ in EUROASPIRE II of smokers reporting cessation compared with 32\% in CONCORDANCE. The reduction in use of a second antiplatelet at 2 years may also reflect adherence to guidelines on the use of dual antiplatelet therapy beyond 1 year, which should be based on the patient's individual thrombotic versus bleeding risks. ${ }^{16}$

The lower rates of use of secondary prevention therapies post-ACS in Australian patients and the observation that one in five patients is rehospitalised within 2 years signify an urgent need to readdress this issue. Strengthening ACS care beyond hospital discharge through encouraging patient attendance at cardiac rehabilitation, ${ }^{5}$ providing alternative models to improve access to cardiac rehabilitation $^{17}$ (eg, tele-health or other innovative models of care), ${ }^{17-20}$ supporting primary healthcare physicians with electronic decision support or quality improvement systems, ${ }^{21}$ and empowering patients in self-management may help to address the relative poverty of post-ACS prevention care in Australia.

Whereas clinical trials are best equipped to examine the efficacy of medical treatments and interventions, it is reassuring that in this observational real-world registry we were also able to demonstrate that use of secondary prevention therapy at discharge and attendance at cardiac rehabilitation were both associated with lower rates of mortality and MACE. These findings further support the existing clinical trial evidence that cardiovascular prevention therapy is beneficial.

\section{Limitations}

The study is observational and involves selected hospitals that volunteered to participate in the CONCORDANCE registry, with little direct incentive. Hospitals and health services that engage in such programmes may be more likely to have an interest in quality improvement and therefore have higher levels of care. Hence, whereas the levels of prevention care reported here are not representative of Australia, they are more likely to overestimate rather than underestimate prevention care. The loss to follow-up rates in this study were likely due to research units being poorly staffed to complete follow-up; however, it is more likely that the patients with complete follow-up are more engaged with their healthcare and likely to have higher rates of treatment. Patients who do not tolerate secondary prevention medications may be sicker and at higher risk of a major cardiac event than those who do; consequently, the benefit associated with use of $>75 \%$ of medications may exaggerate the actual clinical benefit. Finally, the exploratory analysis of the association of prevention treatments and cardiac rehabilitation was done in the subset of patients with follow-up to 2 years.

\section{CONCLUSIONS}

With approximately one in three patients with myocardial infarction in Australian hospitals presenting for their second 
or subsequent time, these observational findings-that use of prevention therapy declines rapidly over time and appears to be worse than in other economically developed countries-make a strong argument for urgently readdressing this issue in Australia. Improving the continued use of cardiovascular prevention in the months and years after a patient's index event is likely to lead to direct and rapid improvements in clinical outcomes. Acknowledgements Sophie Rushton-Smith, PhD (MedLink Healthcare
Communications) provided editorial and writing support and was funded by AstraZeneca.

Collaborators CONCORDANCE Registry: principal investigator and study coordinator: Associate Professor David Brieger and Kitty Xu (Concord Hospital). Investigators and study coordinators: New South Wales: Associate Professor Jens Kilian and Jo-dee Myers (Bankstown-Lidcombe Hospital); Dr Ray Parkin and Anne Morrison (Bathurst Base Hospital); Dr Rohan Rajaratnam and Erin Tattam (Campbelltown Hospital); Dr Jonathon Waites and Clara Baldo (Coffs Harbour Hospital); Dr Kanishka Kamaladasa and Maria Davies (Dubbo Base Hospital); Dr Nicholas Collins and Elizabeth Nyman (John Hunter Hospital); Dr Adam Blenkhorn and Janice Boys (Lismore Base Hospital); Associate Professor Craig Juergens and Elza Plotz (Liverpool Hospital); Associate Professor Drew Fitzpatrick and Lisa Barry (Nepean Hospital); Dr David Amos and Estelle Ryan (Orange Health Service); Dr Mark Adams and Danica Watson (Royal Prince Alfred); Dr Kevin Alford and Rhonda Turnbull (Port Macquarie); Dr Mark Ryan and Karley Robinson (Shoalhaven District Memorial Hospital); Dr James Weaver and Prakriti Shrestha (St George Hospital); Dr Clara Chow and Tracy Tsang (Westmead Hospital); Dr Pratap Chandra Shetty and Renee Stubbs (Wollongong Hospital). Australian Capital Territory: Dr Ahmad Farshid and Pearle Taverner (Canberra Hospital). Northern Territory: Dr Nadarajah Kangaharan and Wendy Corkill (Alice Springs Hospital); Dr Marcus Ilton and Krystal Matthews (Royal Darwin Hospital). Queensland: Dr Steve Coverdale and Colleen Johnston (Nambour General Hospital); Associate Professor Darren Walters and Kathryn Stibijl (Prince Charles Hospital); Dr Rohan Jayasinghe and Helen Gunter (Gold Coast University Hospital); Dr John Atherton and Leeanne Palethorpe (Royal Brisbane and Women's Hospital); Dr Penelope Astridge and Tracey Dalamaras (Toowoomba Health Service); Dr Raibhan Yadav and Tony Farley (Townsville). South Australia: Professor Derek Chew and Fiona Wollaston (Flinders Medical Centre); Associate Professor Christopher Zeitz and Jane Rose (Lyell McEwin); Associate Professor Christopher Zeitz and Marilyn Black (Queen Elizabeth Hospital). Victoria: Dr Paul Antonis and Janise McEwan (Monash Heart): Dr James Shaw and Renee Vandernet (Alfred Health); Associate Professor Omar Farouque and Louise Brown (Austin Hospital); Dr Justin Mariani and Renee Herbstreit (Bairnsdale Regional); Associate Professor Gishel New and Louise Roberts (Box Hill Hospital); Associate Professor John Amerena and Karen Forgarty (Barwon-Geelong Hospital); Associate Professor Willian van Gaal and Mary Park (Northern Hospital); Associate Professor Andrew Maclsaac and Jenny Wilson (St Vincent's). Western Australia: Associate Professor Jamie Rankin and Mary Vorster (The Royal Perth Hospital); Professor Joseph Hung and Louise Ferguson (Sir Charles Gairdner Hospital). Tasmania: Dr Phillip Roberts-Thomson and Teresa Grabek (Royal Hobart Hospital); Dr Bhuwan Singh and Monika a'Campo (Launceston General).

Contributors $C K C$ and DB made substantial contributions to the conception or design of the work. CKC, MR, NK and DB made substantial contributions to the acquisition, analysis or interpretation of data for the work. CKC drafted the work. $\mathrm{MR}, \mathrm{NK}, \mathrm{KKH}, \mathrm{TB}$ and DB revised the manuscript critically for important intellectual content. All authors gave final approval of the version to be published. All authors agree to be accountable for all aspects of the work in ensuring that questions related to the accuracy or integrity of any part of the work are appropriately investigated and resolved.

Funding The CONCORDANCE registry has been supported by grants from AstraZeneca, Sanofi-Aventis, Merck Sharp and Dohme/Schering Plough Joint Venture, Eli Lilly, Boehringer Ingelheim, the National Heart Foundation of Australia, and the National Health and Medical Research Council postgraduate scholarship funding programme. The funders had no role in the study design, data collection and analysis, decision to publish, or drafting of the manuscript. The researchers were independent from the funders. CK Chow is supported by National Health and Medical Research Council of Australia Career Development Fellowship (APP1105447) co-funded by the National Heart Foundation of Australia (100808).

Competing interests None declared.

Patient consent for publication Not required.
Ethics approval The study is performed according to Good Clinical Practice regulations, complies with local regulations and was approved by the research ethics committees at each participating site.

Provenance and peer review Not commissioned; externally peer reviewed.

Open access This is an open access article distributed in accordance with the Creative Commons Attribution Non Commercial (CC BY-NC 4.0) license, which permits others to distribute, remix, adapt, build upon this work non-commercially, and license their derivative works on different terms, provided the original work is properly cited, appropriate credit is given, any changes made indicated, and the use is non-commercial. See: http://creativecommons.org/licenses/by-nc/4.0

\section{REFERENCES}

1. Smolina K, Wright FL, Rayner $\mathrm{M}$, et al. Long-term survival and recurrence after acute myocardial infarction in England, 2004 to 2010. Circ Cardiovasc Qual Outcomes 2012;5:532-40.

2. Antithrombotic Trialists' Collaboration. Collaborative meta-analysis of randomised trials of antiplatelet therapy for prevention of death, myocardial infarction, and stroke in high risk patients. BMJ 2002;324:71-86.

3. LaRosa JC, He J, Vupputuri S. Effect of statins on risk of coronary disease: a metaanalysis of randomized controlled trials. JAMA 1999;282:2340-6.

4. Turnbull F, Blood Pressure Lowering Treatment Trialists' Collaboration. Effects of different blood-pressure-lowering regimens on major cardiovascular events: results of prospectively-designed overviews of randomised trials. Lancet 2003;362:1527-35.

5. Clark AM, Hartling L, Vandermeer B, et al. Meta-analysis: secondary prevention programs for patients with coronary artery disease. Ann Intern Med 2005; 143:659-72.

6. Clark AM, Hartling L, Vandermeer B, et al. Secondary prevention programmes for coronary heart disease: a meta-regression showing the merits of shorter, generalist, primary carebased interventions. Eur J Cardiovasc Prev Rehabil 2007;14:538-46.

7. Kotseva K, Wood D, De Backer G, et al. EUROASPIRE III. Management of cardiovascular risk factors in asymptomatic high-risk patients in general practice: cross-sectional survey in 12 European countries. Eur J Cardiovasc Prev Rehabil 2010;17:530-40.

8. Yusuf $\mathrm{S}$, Islam S, Chow CK, et al. Use of secondary prevention drugs for cardiovascular disease in the community in high-income, middle-income, and low-income countries (the PURE Study): a prospective epidemiological survey. Lancet 2011;378:1231-43.

9. Heeley EL, Peiris DP, Patel AA, et al. Cardiovascular risk perception and evidence-practice gaps in Australian general practice (the AusHEART study). Med J Aust 2010;192:254-9.

10. Aliprandi-Costa B, Ranasinghe I, Turnbull F, et al. The design and rationale of the Australian Cooperative National Registry of Acute Coronary care, Guideline Adherence and Clinical Events (CONCORDANCE). Heart Lung Circ 2013;22:533-41.

11. Fox KA, Dabbous $\mathrm{OH}$, Goldberg RJ, et al. Prediction of risk of death and myocardial infarction in the six months after presentation with acute coronary syndrome: prospective multinational observational study (GRACE). BMJ 2006;333:1091

12. Mathews $R$, Wang TY, Honeycutt $E$, et al. Persistence with secondary prevention medications after acute myocardial infarction: insights from the TRANSLATE-ACS study. Am Heart J 2015:170:62-9.

13. Kassaian SE, Masoudkabir F, Sezavar H, et al. Clinical characteristics, management and 1-year outcomes of patients with acute coronary syndrome in Iran: the Iranian Project for Assessment of Coronary Events 2 (IPACE2). BMJ Open 2015;5:e007786.

14. Maio V, Marino M, Robeson M, et al. Beta-blocker initiation and adherence after hospitalization for acute myocardial infarction. Eur J Cardiovasc Prev Rehabil 2011;18:438-45.

15. Kotseva K, De Bacquer D, Jennings C, et al. Time trends in lifestyle, risk factor control, and use of evidence-based medications in patients with coronary heart disease in Europe: results from 3 EUROASPIRE surveys, 1999-2013. Glob Heart 2017:12:315-22.

16. Valgimigli M, Bueno H, Byrne RA, et al. 2017 ESC focused update on dual antiplatelet therapy in coronary artery disease developed in collaboration with EACTS: The Task Force for dual antiplatelet therapy in coronary artery disease of the European Society of Cardiology (ESC) and of the European Association for Cardio-Thoracic Surgery (EACTS). Eur Heart J 2018;39:213-60.

17. Jelinek M, Vale MJ, Liew D, et al. The COACH program produces sustained improvements in cardiovascular risk factors and adherence to recommended medications-two years follow-up. Heart Lung Circ 2009;18:388-92.

18. Chow CK, Redfern J, Hillis GS, et al. Effect of lifestyle-focused text messaging on risk factor modification in patients with coronary heart disease: a randomized clinical trial. JAMA 2015:314:1255-63.

19. Neubeck L, Freedman SB, Briffa T, et al. Four-year follow-up of the choice of health options in prevention of cardiovascular events randomized controlled trial. Eur J Cardiovasc Prev Rehabil 2011;18:278-86.

20. Lafeber M, Spiering W, Visseren FL, et al. Impact of switching from different treatment regimens to a fixed-dose combination pill (polypill) in patients with cardiovascular disease or similarly high risk. Eur J Prev Cardiol 2017;24:951-61.

21. Schouten LM, Hulscher ME, van Everdingen JJ, et al. Evidence for the impact of quality improvement collaboratives: systematic review. BMJ 2008:336:1491-4. 